\title{
Oppliger, P. A., \& Shouse, E. (Eds.) The Dark Side of Stand-Up Comedy. Palgrave Macmillan, 2020, 320 pp, eBook ISBN: 978-3-030-37214-9, Hardcover ISBN: 978-3-030-37213-2, Hardback 96,29 €
}

The reason [people make dark jokes] is they are trying to bring a level of humanity-laughter-back to a moment that seems to lack it: tragedy. They're trying to make you, the individual, laugh in your moment of sadness so just for the briefest of seconds, you have a minor moment of respite where you forget how shit things are and you get to have a giggle with yourself. But what that does manifest itself as is... they say fucked-up things.

Daniel Sloss, Jigsaw (2018)

Daniel Sloss, a Scottish stand-up comedian, in his opening bit of the Netflix special Jigsaw (2018), admits to having "evil thoughts" and proceeds to describe the joy he feels when he imagines a young boy tripping and falling on his face. Although his audience does not share his views, they still laugh at the absurdity, or rather immorality,

1 Address for correspondence: Faculty of Philology, University of Białystok, Pl. NZS 1, 15-420 Białystok, Poland. E-mail: j.wawrzyniuk@uwb.edu.pl 
of the pleasure he describes. Sloss then tries to redeem himself in his audience's eyes and says that "evil thoughts don't make you evil; acting on them does." This stance could be well translated as a perception of dark humor, which, for many, seems to be a significant characteristic of stand-up comedy. Telling dark jokes does not mean a comedian is troubled (or traumatized). Moreover, darkness and trauma can be both causes and results of dark humor.

These points are proven in one of the most recent volumes of the Palgrave Studies in Comedy series. The Dark Side of Stand-Up Comedy, edited by Patrice A. Oppliger and Eric Shouse, is a collection of articles and essays that look at the darkness of stand-up from both within and outside of the comedy scene. The authors, who include scholars and stand-up comedians, tackle the troubled comic trope and discuss the theories of the stereotype. They explore the lightness and darkness of stand-up comedy from various aspects, often focusing on angles that do not evoke such connotations; the darkness ranges from the "usual" tragic and gruesome themes of death, suicide, and abuse to the surprising, but equally dark, aspects of physical violence, sacrifice, and monotony. Even avid enthusiasts may not be aware of the latter themes.

The book is divided into two parts. The first part, with eight chapters, is devoted to the workings of stand-up comedy and its association with dark humor. Scholars examine the darkness using the benign violence theory (McGraw \& Warren, 2014) and discuss professional comedians' lives and their connections to dark humor. The second part, with seven chapters, focuses on amateur and lesser-known comedians and their struggles to engage in the stand-up comedy scene.

In the first chapter, Eric Shouse discusses comedians' personal lives, comic stage personas, and acts. He addresses the darkness of death, suicide, and drug addiction in stand-up comedy through the work and biographies of George Carlin, Richard Pryor, and Robin Williams. These "founding fathers of stand-up comedy" are excellent examples of the troubled comedian trope, but the author comes to the conclusion that the darkness comes from different sources and is reflected differently, therefore should not be generalized. In other words, dark humor does not automatically indicate mental health issues or substance abuse.

The second chapter discusses changes that George Carlin had to make in his "I Kinda Like It When a Lotta People Die” bit in the wake of the 9/11 terrorist attacks. Steven S. Kapica explores how Carlin's approach to the routine allowed for catharsis in a time of tragedy and uneasiness among his audience members. As Sloss says, bringing laughter to a moment of sadness, even with the best of intentions, requires tact and taste, and Carlin was able to do that well in his routine.

The third chapter explores childhood trauma as a reason for and source of comedy and comedic style. Sean Springer takes a close look at Steve Martin's work and its connection to his relationship with his emotionally distant father. He shows how trauma influences 
a comedian's choices and how, at the same time, the choices can be an attempt to stand in opposition to the darkness within a comic.

Philip Scepanski, in the fourth chapter, scrutinizes how alcohol addiction and its repercussions can be turned into a humorous monologue. He looks at Craig Ferguson's biography and work and shows that ridiculing celebrities who suffer from addiction and mental health problems is morally questionable at best. This chapter describes the comedic catharsis that comes from a comedian's own "darkness," as opposed to the catharsis analyzed in the second chapter, which was an answer to tragedy happening in the world.

As the editors comment, "whether one agrees with Ferguson's point that it is morally suspect to mock 'vulnerable people,' it is a different question entirely whether doing so should be illegal" (p. 43). In the fifth chapter of this part, Christelle Paré looks at the court case Mike Ward v. The Quebec Human Rights Commission. The case and its origins create a sort of paradox of darkness: Mike Ward, a comedian known for his charitable work for and support of physically challenged people, repeatedly made fun of a disabled teenager. Ward claimed that his jokes had a different objective than ridicule. This case and similar ones beg the question of defining the moral and legal limits of stand-up comedy. Notably, if many limitations were imposed, they would eventually take the form of censorship.

In the sixth chapter, Carey Marie Noland and Michael Hoppmann uncover the dark humor of Jim Gaffigan's seemingly clean jokes, which frequently include the glorification of food addiction and morbid obesity. The darkness present in Gaffigan's work is another instance of paradoxical darkness. It becomes more apparent upon scrutiny; the dark layer of his humor is hidden behind the light-hearted jokes. As the authors state, "[t]he interplay of self-deprecation and the dark topic allow him to transform the pain and danger of food addiction into laughter" (p. 238). Noland and Hoppmann use the benign violence theory to illustrate how Gaffigan, as well as Gabriel Iglesias and others, admit to norm violation and make a joke out of it.

The seventh chapter is especially important in the wake of the \#MeToo movement. While stand-up comedy scene has come a long way from the "women are not funny" stereotype (Krefting 2014), it is still a male-dominated arena. Female comics are still subjected to sexism and sexual misconduct by male colleagues and audience members. In this chapter, Patrice A. Oppliger and Kathryn Mears use communication theories to examine how humor can be used to cover and uncover immoral behavior. They give the examples of Bill Cosby, Al Franken, and Louis C.K., all of whom behaved inappropriately and were excused by the public for a long time but now have been made accountable.

The last chapter of this part revolves around the topic of mental health. Kathryn Mears, Eric Shouse, and Patrice A. Oppliger explore the work and comic persona of Maria Bamford. In her comedy, Bamford openly talks about being bipolar, and therefore, she successfully opens a discussion of a topic that still may be considered taboo. 
The authors question the validity of the benign violence theory (McGraw \& Warren 2014) as it might relate to Bamford's work. All in all, she views the darkness of mental illness with a new perspective (or, ironically, in a new light).

As I mentioned before, the first part of the text is made up of contributions by scholars discussing the dark humor in stand-up comedy from the perspectives of philosophical, psychological, and humor research. Here, unsurprisingly, dark humor is associated with death, addiction, terrorism, disability, and child and sexual abuse, topics that are traditionally, and rightfully, "unlaughable." If a convention is broken and jokes do involve these topics, they are considered dark. However, the notion that dark humor originates from dark and twisted minds is a gross simplification of stand-up comedy. What is more, this notion is based on the work of comedian-celebrities, who are a tiny fraction of the vast number of comics on the comedy scene, especially in the United States.

That is why it is even more fascinating that the second part of this book is devoted to lesser-known comedians who treat stand-up more as a hobby than a job (most of them have full-time jobs that allow them to make a living so they can do comedy on the side). It consists of discussions, reports of interviews, and essays with responses coming from scholars and people who have experience in stand-up comedy. As it turns out, the darkness in stand-up is more than tragedy: it can often take the least expected form of perfecting the craft or the passage of time.

In the first chapter of the second part, Sheila Lintott tackles the "troubled stand-up stereotype" and its "mad scientist" origins. The paradoxical darkness of that trope lies in the notion that comedians are thought of as truth-bearing, honest, and sometimes even rebellious, and that their act on stage is the same as their "act" offstage. As a matter of fact, the studies show that most amateur comedians are far from being dark or troubled and that a successful performance requires a lot of time and effort in order to seem effortless and spontaneous. If done right, stand-up comedy looks easy; when something goes wrong, however, the audience's rejection feels very personal.

The next chapter follows the mechanisms of stand-up comedy and defines and highlights the distinction between a person and a stage persona. Edward David Naessens discusses how, in his experience, an audience does not take into account the years of crafting but rather mistakes in an act of the persona of for the comedian's true personality.

The following chapter describes the real and very physical danger of performing comedy. Stand-up comedy is often considered shocking and vulgar in the first place (Brodie 2014), but if fuel is added to the fire in the form of dissatisfied audience members who may be drinking alcohol, the feelings become intensified. Eric Shouse reports on his interviews with stand-up comedians who relate that heckling and threats are widespread reactions but that physical violence (provoked or not) is just as common. A feeling of defenselessness on the part of amateur comedians is an often overlooked dark side of stand-up comedy. 
In the following chapter, Blayr Nias tells the story of a drunk audience member who harassed her when she was on stage and sexually assaulted her afterward. Nias reframes the story and changes the perception of her character from a victim to a protagonist, thereby bringing light to the darkness of being a female comic in the male-dominated stand-up comedy scene.

Subsequently, in a powerful essay, "The Ethics of Rape Jokes," Cait Hogan reflects on the importance of comedy in processing traumatic experiences and how transforming tragedy into comedy takes courage and a certain risk that is hard to calculate. Standup comedy's first and foremost goal is to entertain (Brodie 2014), but this can be done while also being vocal and asking difficult questions. The only caveat may be that the comedian must have an awareness of what can or should not be said so as not to alienate the audience or bring back the trauma for the comedian and audience members. Fortunately, there is a wave of change coming; Hannah Gadsby, Iliza Shlesinger, Daniel Sloss, and many more comedians speak about their experiences of sexism and sexual misconduct openly even though this may affect their connections to the comedy industry. What is more, and paradoxically for comedians, they could not be more serious when speaking about these topics.

The second-to-last story shows the enormous sacrifices that lesser-known comedians have to make to fulfill their dreams of performing for a couple of minutes at a bar full of inebriated people. Louis Bishop gives an excruciatingly detailed description of his work as a mortuary assistant, showing how far an aspiring comedian is willing to go to earn a living and also pursue something that resembles a career in show business.

The final chapter is a stark reminder that comedian-celebrities are a minority who are lucky enough to make money from their hobby; this is not a given for lesser-known comics. Larry Fulford talks about something that an average audience member does not take into account when thinking about comedians: how much time it takes to hone a routine. Stand-up comedy is a heavily one-sided interaction but an interaction nonetheless (Brodie 2014). A comedian cannot perfect a set without an audience, and countless gigs and open mics are needed to do this. The darkness of this aspect is associated with the realization that time must be regularly "wasted" to derive a few moments of joy from doing what a comedian loves. The ultimate darkness, however, comes from understanding that the longer a comedian stands on a stage, the more the hobby turns into a job.

The Dark Side of Stand-up Comedy offers a nuanced yet essential insight into the darkness and workings of the stand-up comedy scene. The editors' goal was to tackle the oft-repeated trope of the "troubled comedian." They managed to do so in a way that can be of use not only to scholars but also to regular fans of stand-up comedy. The language and theory supporting the arguments are presented in a clear way that does not require prior knowledge of the humor research field. The main value of the book is its attempt to include and discuss the perspectives of both famous and lesser-known comedians. 
Frankly, the latter are underrepresented in the research despite being the majority in the vast industry of stand-up comedy. In conclusion, this collection successfully sheds light on the paradoxical and multidimensional aspect of the darkness of comedy, which is as incongruous as humor itself.

\section{References}

Brodie, I. 2014. A Vulgar Art: A New Approach to Stand-Up Comedy. University Press of Mississippi.

Krefting, R. 2014. All Joking Aside: American Humor and Its Discontents. Baltimore: Johns Hopkins University Press.

McGraw, A. \& Warren, C. 2014. Benign violation theory. In: S. Attardo (ed.), Encyclopedia of Humor Studies, 75-77. Thousand Oaks: SAGE Publications, Inc.

Oppliger, P. A. \& Shouse, E. (eds.). 2020. The Dark Side of Stand-Up Comedy. London: Palgrave Macmillan.

Sloss, D. (creator). 2018. Jigsaw. [Video file] Retrieved from http://netflix.com

$$
* * *
$$

Justyna Wawrzyniuk is a $\mathrm{PhD}$ student and a research assistant at the Faculty of Philology of the University of Bialystok in Poland. Her doctoral thesis is a metaphor-led discourse analysis of gender construction in stand-up comedy. 